\title{
A Fast Protection Scheme for TCSC Compensated Transmission Line Using Wavelet-Alienation-Neural Technique
}

\author{
Bhuvnesh Rathore ${ }^{1}$, Amit Gangwar ${ }^{2}$, Om Prakash Mahela ${ }^{3}$, baseem khan ${ }^{4}$, and \\ Sanjeevikumar *Padmanaban ${ }^{5}$ \\ ${ }^{1} \mathrm{JIET}$ \\ ${ }^{2}$ Government Engineering College Jhalawar \\ ${ }^{3}$ Indian Inst Technol \\ ${ }^{4}$ Hawassa University \\ ${ }^{5}$ Aarhus Universitet Science and Technology
}

May 11, 2021

\begin{abstract}
This paper proposes a security algorithm based on thewavelet-alienation-neural technique for detecting, classifying, and locating faults on Thyristor-Controlled Series compensator (TCSC) compensated lines. A fault index has been calculated using wavelet transform and alienation coefficients with post-fault current signals measured/ sampled for quarter cycle time at both near and far end buses for fault detection and classification. The location of the fault is predicted using an Artificial Neural Network (ANN) after the fault has been diagnosed. Approximate coefficients (quarter cycle time) of both voltage and current signals, from both buses, were provided as input to ANN. Various case studies, such as variations in TCSC position, fault location, sampling frequency, power flow path, incipient angle of fault, TCSC control strategy, fault resistance, and load switching conditions, have verified the robustness of the proposed safety system.
\end{abstract}

\section{Hosted file}

A_demonstration_of_the_LaTeX_class_file_for_Wiley_NJD_Journals.pdf available at https:// authorea.com/users/413124/articles/521562-a-fast-protection-scheme-for-tcsc-compensatedtransmission-line-using-wavelet-alienation-neural-technique 